\title{
An insight into the change in the doubling time of COVID-19 in Pakistan
} \author{
Murad khan ${ }^{4}$ and Bashir Ahmad ${ }^{5}$ \\ 1. Department of Zoology Abdul Wali Khan University Mardan-Pakistan \\ 2. Department of Chemistry Jahanzeb College Saidu Sharif Swat-Pakistan \\ 3. Government Girls Degree College Mansehra-Pakistan \\ 4. Department of Botany Islamia College University Peshawar-Pakistan \\ 5. Department of Zoology Islamia College University Peshawar-Pakistan \\ *Corresponding author's email: attakhan_154@yahoo.com
}

Attaullah $^{1 *}$, Ismail Zeb ${ }^{1}$, Nasir Iqbal ${ }^{2}$, Khurshaid Khan ${ }^{1}$, Nehafta Bibi ${ }^{3}$,

Citation

Attaullah, Ismail Zeb, Nasir Iqbal, Khurshaid Khan, Nehafta Bibi, Murad Khan and Bashir Ahmad. An insight into the change in the doubling time of COVID-19 in Pakistan. Pure and Applied Biology. Vol. 10, Issue 1, pp54-61. http://dx.doi.org/10.19045/bspab.2021.100007

\begin{tabular}{llll}
\hline \hline Received: 10/05/2020 & Revised: 11/08/2020 & Accepted: 18/08/2020 & Online First: 26/08/2020 \\
\hline \hline
\end{tabular}

\section{Abstract}

Since the outbreak of Coronavirus Disease 2019 (COVID-19) in Pakistan, several studies generated valuable estimations at early stages by tracing the cases with deference to time for the establishment of more operative interventions. Therefore, this study examined the changes in the infection rate for COVID-19 in Pakistan using the data $\left(26^{\text {th }}\right.$ February to $15^{\text {th }}$ May 2020) recorded by National Institute for Health. A choropleth map was generated using ArcGIS software for spatial distribution and epidemiological Susceptible, Infected, and Recovered (SIR model) was applied to estimate the epidemic trend of COVID-19. Change in the doubling time of cases and the fatality rate were estimated using the folded formula by classifying the recorded data in nine categories keeping eight days interval. Till $15^{\text {th }}$ May, 2020, total confirmed cases were 37218 with highest cases in Sindh (14099), deaths in Khyber Pakhtunkhwa (284) and least cases and deaths in Azad Jammu Kashmir $(105,1)$ respectively. COVID-19 cases were elevated from $26^{\text {th }}$ February to $29^{\text {th }}$ April except $30^{\text {th }}$ April to $3^{\text {rd }}$ May followed by the exponential increase till $15^{\text {th }}$ May. The cases and fatality rate was increased 3.7 times and 5.4 times from category 2 to 3 and 3 to 4 respectively. The least cases and fatality rate were 1.4 and 0.6 times increased from category 8 to 9. The increase in the number of infections was slow during the initial stage of the outbreak, due to the immediate lockdown in the various region of the country. If containment measures are lifted abruptly, a renaissance of cases is to be expected.

Keywords: COVID-19; Containment measures; Drastic changes; Passengers; Pakistan

Introduction

Novel coronavirus Diseases 2019 (COVID-

19) related to pneumonia-like illness, and allied with a virus, previously reported by Chinese health authorities on $7^{\text {th }}$ January, 2020 and first recorded death on $11^{\text {th }}$ January. The virus was given a new name (Severe
Acute Respiratory Syndrome Coronavirus-2) SARS-CoV-2 [1]. World Health Organization (WHO) then confirmed the causative agent as a public health emergency of international concern and health departments on a global scale [2]. Previously in December 2019, the epidemiological 
association of patients with viral pneumonia was found to be connected with the Huanan seafood market of the commercial center and the sprawling capital city "Wuhan" of Central China's Hubei province. Dated back to $13^{\text {th }}$ January 2020 ; the first COVID-19 case was reported in Thailand outside China and after that several other countries documented the introduced of COVID-19 in their population. Till $29^{\text {th }}$ January 2020 , a total of 5,997 COVID-19 cases were reported in China and 68 confirmed cases in several other countries [3]. The infection has been testified in family masses, health workers, and also human to human transmission has been reported [4]. In the past twenty years, two highly pathogenic human Corona Viruses (HCoVs); Middle East respiratory syndrome coronavirus (MERS-CoV) and severe acute respiratory syndrome coronavirus (SARS-CoV) have been evolved zoonotically and led to worldwide epidemic with high mortality and morbidity $[5,6]$. In severe cases acute respiratory distress syndrome (ARDS), acute cardiac injury, respiratory failure the patients require invasive ventilation, oxygen therapy or extracorporeal membrane oxygenation and death may occur [7]. WHO declared the COVID-19 as a global pandemic on $11^{\text {th }}$ March, 2020, and approximately 120,000 plus cases were reported on $13^{\text {th }}$ March, 2020, with over 45, 00 casualties in around 100 countries [8]. COVID-19 is ravaging throughout the world especially in Italy, France, Spain, and the United States [9]. Pakistan has suffered a great deal from infectious disease such as dengue [10], and the pandemicity of COVID-19 has just begun which is a major challenge around the globe. For this purpose, the study is planned to determine and estimate the initial risks of Novel Coronavirus 2019 transmission from foreign countries and determine its increase in folds to make preplanned decision to prevent its further dispersion in the country with its prime effect on Pakistan.

\section{Materials and Methods Data collection}

Daily documented data of COVID-19 confirmed cases and death casualties was collected from the official websites of National Institute for Health (NIH) and assorted. Data concerning one million passengers and Iranian zaireen (people returning from Iran after visiting and worshiping holy places), Umrah zaireen (people returning from Mecca and Madina after visiting and worshiping holy places) and several other countries was also collected and screened from the official daily situation reports websites of health department government of Pakistan. All the recorded data was collected in 2020 from a period of $26^{\text {th }}$ February to $15^{\text {th }}$ May.

\section{Data analysis}

Documented data of COVID-19 and returned passengers was assorted in the spreadsheets of Microsoft Excel and data representative graphs were prepared (Window version 2013). For spatial analysis coordinates of each airport (entries focal points of infected neighboring or other countries passenger), diagnostic laboratories, and quarantine centers were tagged on Pakistan map. A choropleth map was generated representing the highest and least COVID-19 cases at provincial level of Pakistan. SIR model was used for the epidemiological prediction of the expected number of infected cases [11]. For the determination of change in the doubling time of COVID-19 and fatality rate in folds, we divided new cases by the original number to determine the fold change for an increase.

\section{Results}

After the incidence of COVID-19 in China, Iran reported the highest number of cases in Asia. In Pakistan, the first two COVID-19 cases were reported on $26^{\text {th }}$ February in the Iranian passenger which mobilized the governmental bodies and caused the 
Barricade of Taftan border with Iran, alongside passenger of other countries have also returned (Fig. 1). Several hundred infected passengers were freely released to their residencies from where the spread of COVID-19 initiated and actively transmitted in the mainland of Pakistan at various foci. The influences of infected passengers were then decreased but the trend of local transmission increased throughout the country.

Changes in the transmission rate had a clear effect on the proportion of infections that were identified and counted as confirmed cases. As from $26^{\text {th }}$ February to $15^{\text {th }}$ May the total COVID-19 confirmed cases and deaths were 37218 and 803 respectively. A choropleth map displaying the highest occurrence of COVID-19 cases in Sindh (14099 cases, 243 deaths) and Punjab (13914, 234) followed by Khyber Pakhtunkhwa (5423, 284), Balochistan (2310, 30), Islamabad (866, 7), Gilgit (501, 4), and Azad Jammu Kashmir (105, 1) (Fig. 2).

Total confirmed cases and deaths with respect to date were classified keeping four days interval (Fig. 3). From $26^{\text {th }}$ February to $29^{\text {th }}$ April an elevated trend in the occurrence of COVID-19 cases have been observed except the $30^{\text {th }}$ April to $3^{\text {rd }}$ May followed by exponential increase till $15^{\text {th }}$ May. At the start of COVID-19 eruption in Pakistan the number of positives cases was lesser, and often this number did not change for several days. From $5^{\text {th }}$ April to $15^{\text {th }}$ May shows the doubling period as it has changed during the end of April, for all provinces. Using NIH for
COVID-19 situation dashboard a spreadsheet of daily case numbers was collated for all the provinces. For each province, the number of positives cases on a given day was then associated with numbers on next days, until the number surpassed $2 \times 2$, roughly, on Day 6. Intercalating linearly between Day 5 and Day 6 produced the decimal number of days taken to dual the number of positive cases. The process was then stepped forward starting at Day 1, to find how many days were required to double the number of COVID-19 cases, repeating through the dataset.

We modeled the effects of changes in the number of cases and fatality rate. A drastic change of COVID-19 cases and fatality was observed throughout the duration of the study. The time increased in the proportion of COVID-19 cases and fatality was noted (2.7, 0 ) from category 1 to 2 , followed by category 2 to $3(3.7,3.4)$, category 3 to $4(2.1,5.4)$, category 4 to $5(1.9,2.4)$, category 5 to $6(1.7$, $1.3)$, category 6 to $7(1.9,0.9)$, category 7 to $8(1.4,1.0)$, and category 8 to $9(1.6,0.6)$ (Fig. 4).

We find that for a wide range of model, the cases are well reproduced by SIR model. The total population of Pakistan (212 million) was assumed to be susceptible to this disease. The total number of infected cases 37218 and recovered cases 1015 were used in this prediction. Considering the rate of recovery $\gamma$ value 0.137 was used and $\beta$ value 0.648 was used for the prediction (Fig. 5). The data predicts that nearly 98 million of the population is likely to become infected at the $20^{\text {th }}$ day. 


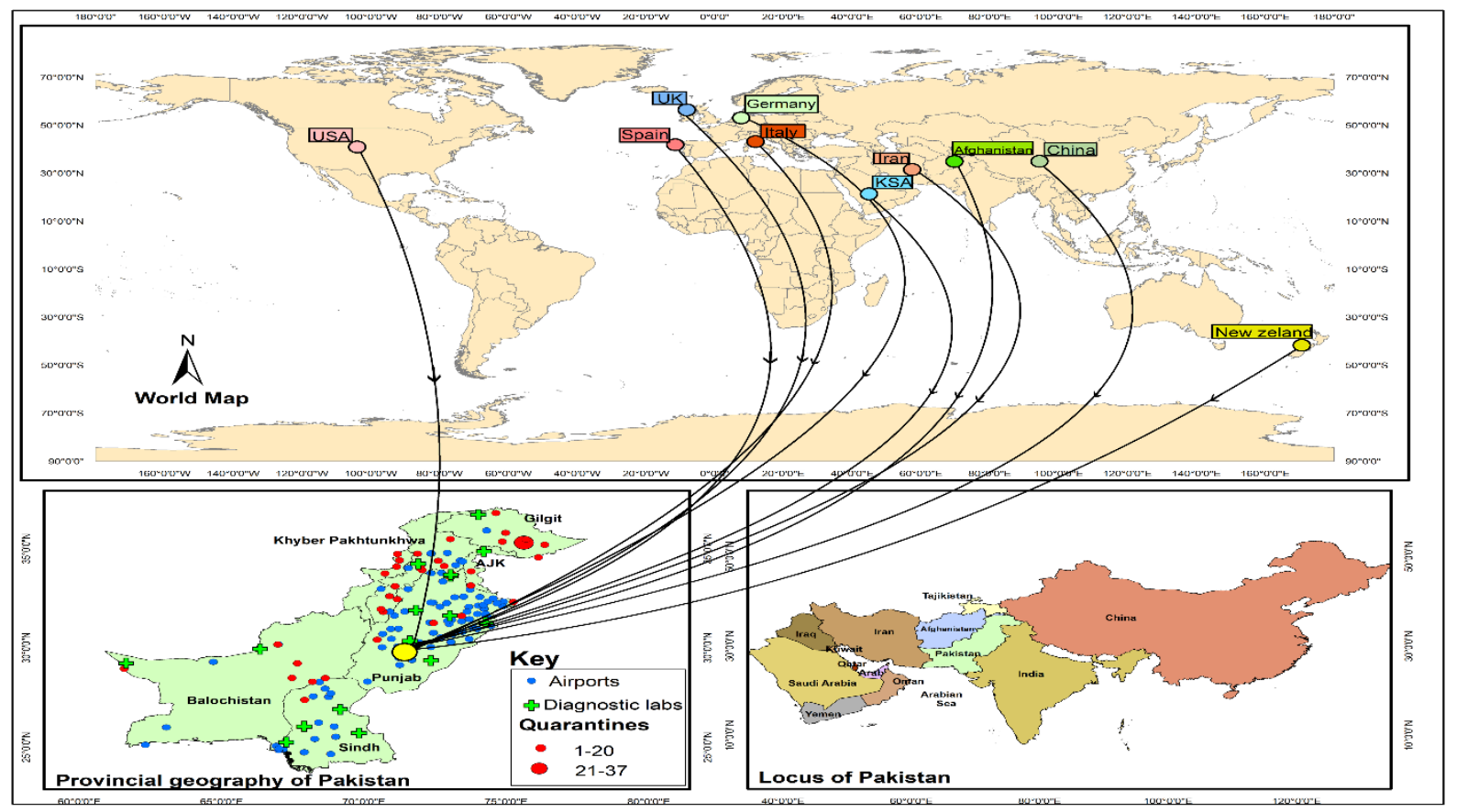

Figure 1. Represents the influx of returned passengers from various countries to Pakistan (indicated with lines), locus of Pakistan, and provincial level airports, COVID-19 quarantine centers and diagnostic laboratories in various regions of Pakistan

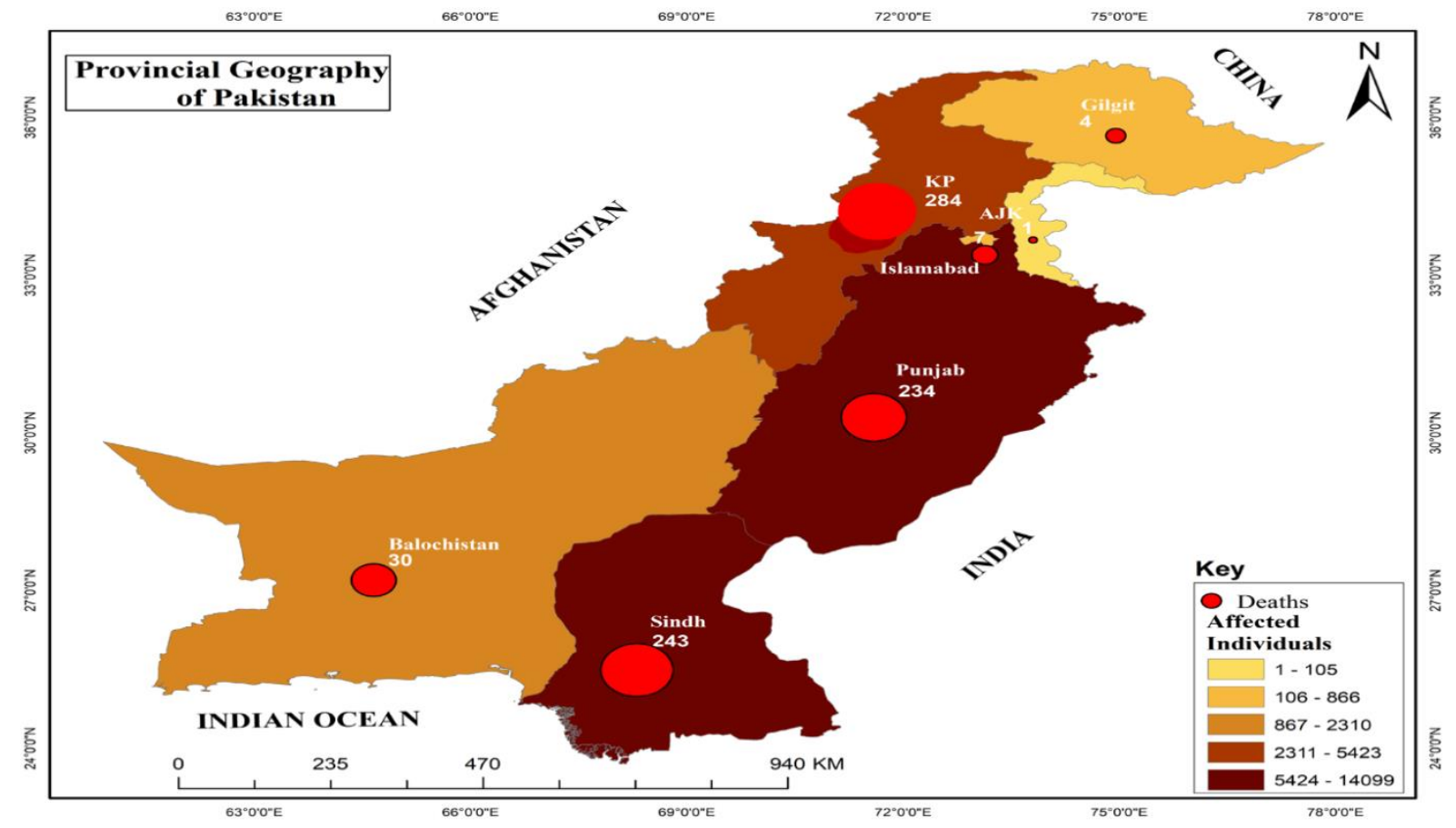

Figure 2. Represents province wise total COVID-19 confirmed and death causalities in Pakistan on choropleth map 


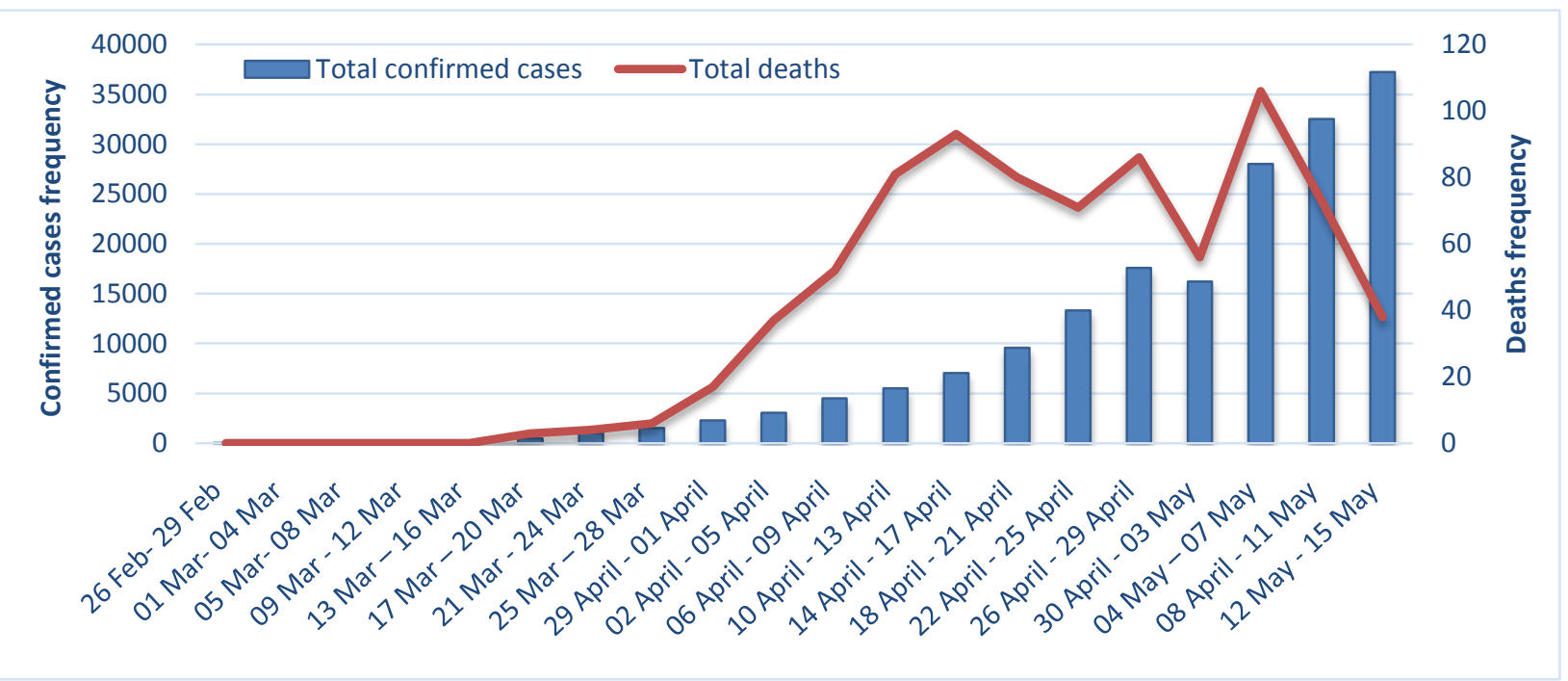

Figure 3. Represents COVID-19 cases and death causalities frequencies at interval of four day

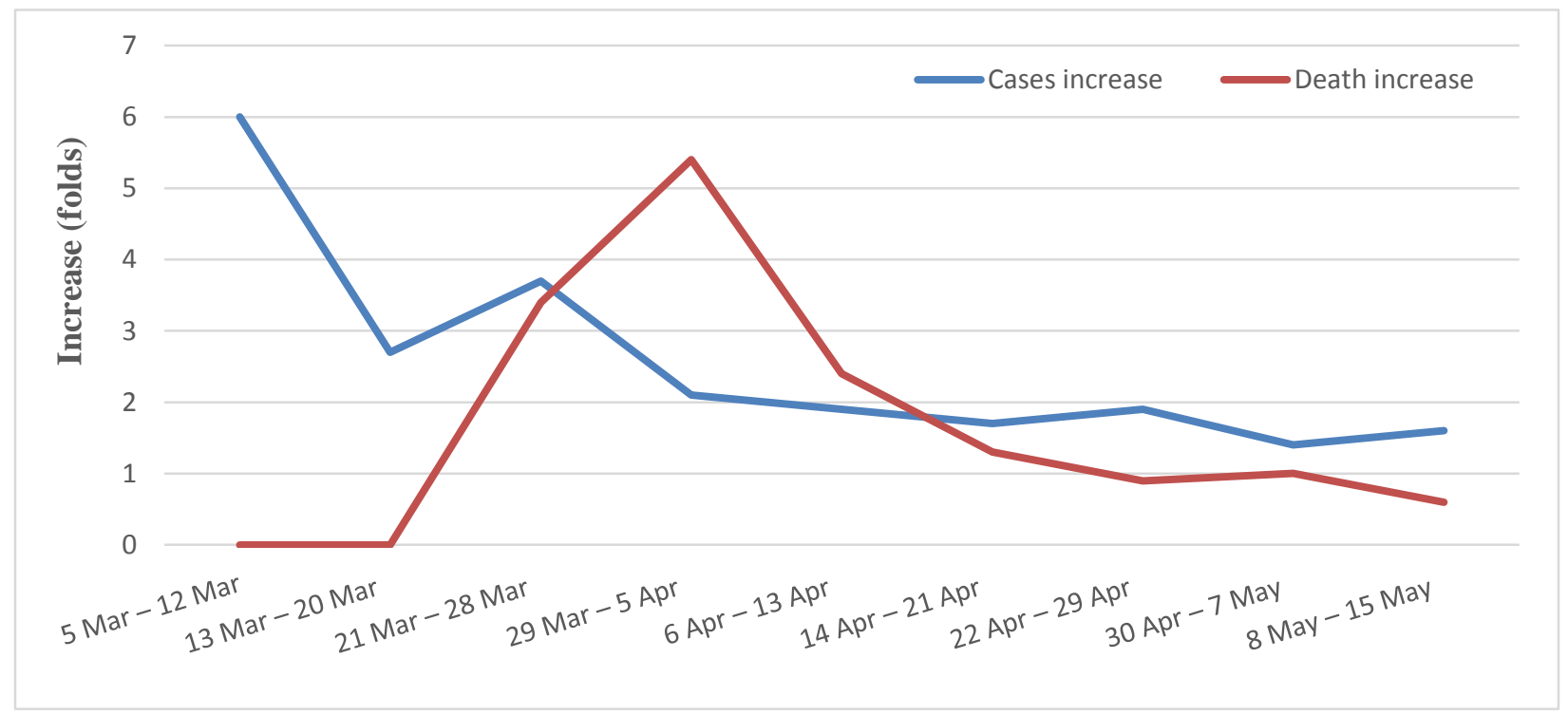

Figure 4. Showing COVID-19 confirmed cases and deaths increase in folds 


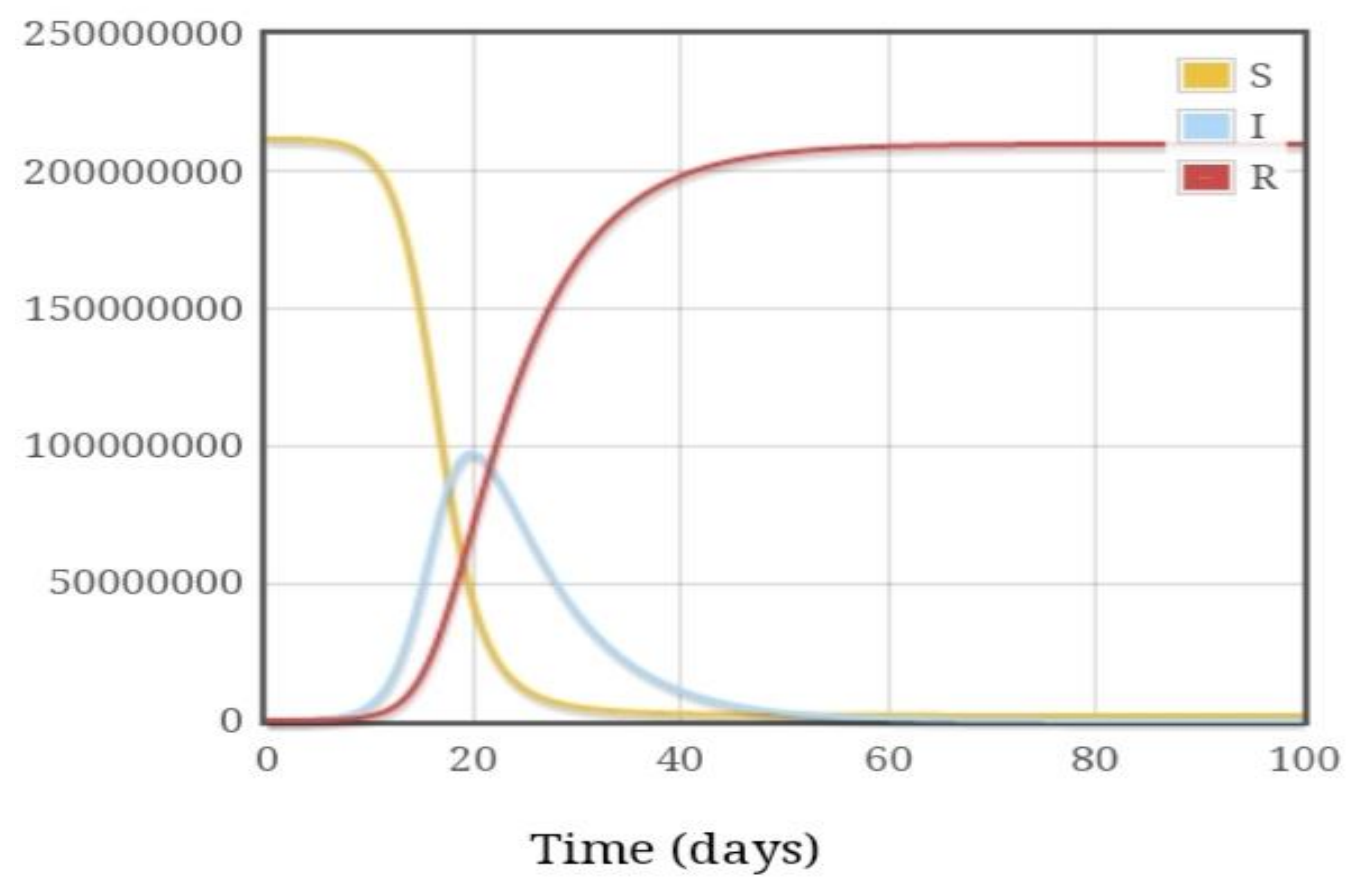

Figure 5. Epidemiological Prediction of suspected, Infected and Recovered population from COVID-19

\section{Discussion}

In summary, the present study elucidated the key features of the COVID-19 epidemic dynamics in Pakistan showing the exponential rise in the number of confirmed cases. It was estimated that changes in the number of COVID-19 cases in Pakistan led to stepwise increases in different region of the country. Highest COVID-19 cases have been reported from category 2 to 3 (3.4 times increased) and least occurrence was found from category 7 to 8 (1.4). It is pertinent to mention here that $81 \%$ of COVID-19 infection cases are of mild in nature (symptomatic or asymptomatic), 14\% develop a severe disease that requires treatment and 5\% cases are critical mostly involve the individuals with co-morbidities like hypertension [12]. Considering this, 5\% of the infected populations that make 10.6 million of the individuals are predicted to come and use the hospital facility. As of $15^{\text {th }}$ May 2020 the case fatality rate in Pakistan is recorded as $2.1 \%$, which is considerably high as compared to the confirmed cases. The numbers of fatality rate were increased 3.4 times from category 2 to 3 , and least was found 0.6 times from segment 8 to 9 . The risk of dying from COVID-19 has a direct relationship with the age of the individual. This data suggests that the countries having more population of older age have a higher case fatality rate of COVID-19. As Pakistan has only a small population of age 65 years or above, the case fatality rate of COVID-19 will remain less in Pakistan with proper medical care as compared to China, Italy, and Spain.

The number of individuals who were infected is likely to be greater than 37218 because many mild cases were not tested or confirmed, and some infections were asymptomatic [13]. The estimated case numbers were considerably higher than the observed case numbers, suggesting a socalled clinical iceberg phenomenon, which is common for a disease that can cause both mild and severe illnesses like COVID-19 
[14]. The risk of dying increases with age and co-abnormalities. Hence, most of the deaths from COVID-19 observed in individuals older than 60 years, particularly those with chronic abnormalities like cardiac diseases [15]. Pakistan has only $4.44 \%$ individuals age 65 years or above that is considerably less compared to China (12.34\%), Italy (22.08\%), Spain (18.49\%) and Iran (5.87\%) [16]. Fatality rate in Pakistan is $2.1 \%$ which is high as compared to the confirmed cases. The reported fatality rate in china was $2.3 \%$ that is substantially lower than Italy (7.2\%), Spain (7.3\%) and Iran (7.6\%) [17]. During the outbreak of dengue Pakistan is considered an endemic center this study also considered that Pakistan is now endemic in coronavirus. The model further suggests that the public response to the epidemic and the containment measures put in place by the Pakistani government were effective despite the increase in confirmed cases. That this behavior was universally observed in all provinces also indicates that mitigation strategies were universally effective. Based on our analysis, we argue that the implemented containment strategies should stay in effect for a longer time than the incubation period after the saturation in confirmed cases sets in for this particular outbreak. Our analysis further implies and provides evidence that mitigation strategies that target the susceptible population and induce behavioral changes at this "end" of the transmission process are most effective to contain an epidemic especially in situations when asymptomatic or mildly symptomatic infectious periods are long or their duration unknown. This may be of importance for developing containment strategies in future scenarios or if the current COVID-19 epidemic were to trigger large scale outbreaks in other regions of the world by exports and subsequent proliferation.

\section{Conclusion and Recommendation}

The COVID-19 hubs were Sindh and Punjab provinces and least occurred in Azad Jammu Kashmir. Throughout the study period the COVID-19 cases was found elevated with an exponential increase till $15^{\text {th }}$ May, 2020 showing the 3.7 and 5.4 times increased in cases and fatality rate respectively. Basic preventive measures should be promoted appropriately and applied by each individual especially avoidance of unnecessary travelling to resist the transmission of COVID-19 Peculiarly. This might be of significance for emerging containment policies for currently developing large-scale secondary outbreaks of COVID-19 in numerous regions of the world or future eruptions of other contagious diseases.

\section{Authors' contributions}

Conceived and designed the experiments: Attaullah \& K Khan, Performed the experiments: I Zeb \& B Ahmad, Analyzed the data: N Iqbal, Contributed materials/ analysis/ tools: M Khan, Wrote the paper: $\mathrm{N}$ Bibi.

\section{Acknowledgement}

The authors acknowledge defend armed force, medical staff and researchers all around the world who are fighting on the frontline against COVID-19 pandemic.

\section{References}

1. Bialek S, Gierke R, Hughes $\mathrm{M}$, McNamara LA, Pilishvili T \& Skoff T (2020). Coronavirus Disease 2019 in Children United States. Morbidity and Mortality Weekly Rep 69(14): 422.

2. Guan WJ, Ni, ZY, Hu Y, Liang, WH, Ou CQ, He JX, \& Du B (2020). Clinical characteristics of 2019 novel coronavirus infection in China, MedRxiv.

3. Lu R, Zhao X, Li J, Niu P, Yang B, Wu $\mathrm{H}, \quad \&$ Bi Y (2020). Genomic characterisation and epidemiology of 2019 novel coronavirus: implications for 
virus origins and receptor binding. The Lancet 395(10224): 565-574.

4. Riou J, \& Althaus CL (2020). Pattern of early human-to-human transmission of Wuhan 2019 novel coronavirus (2019nCoV), December 2019 to January 2020. Eurosurveillance 25(4): 2000058.

5. Paules CI, Marston HD, \& Fauci AS (2020). Coronavirus infections-more than just the common cold. Jama 323(8): 707-708.

6. Wu JT, Leung K \& Leung GM (2020). Nowcasting and forecasting the potential domestic and international spread of the 2019-nCoV outbreak originating in Wuhan, China: a modelling study. The Lancet 395(10225): 689-697.

7. Wang $\mathrm{D}, \mathrm{Hu} \mathrm{B}, \mathrm{Hu} \mathrm{C}, \mathrm{Zhu} F$, Liu X, Zhang J, \& Zhao Y (2020). Clinical characteristics of 138 hospitalized patients with 2019 novel coronavirusinfected pneumonia in Wuhan, China. Jama 323(11): 1061-1069.

8. World Health Organization. Briefing on COVID-19. (2020) Retrieved from https://www.who.int/dg/speeches/detail/ who-director-general-sopeningremarks-at-the-media-briefing-oncovid-19-9-March-2020

9. Nioi M, \& Napoli PE. (2020). Global Spread of Coronavirus Disease 2019 and Malaria: An Epidemiological Paradox. Available at SSRN; 3554389.

10. Attaullah, Iqbal N, Khan GN, Yousafzai AM, Karimullah, Ahmad N, Khan S \& Wadood F (2017). Incidence of dengue virus eruption in Swat, Khyber Pakhtunkhwa, Pakistan. Asian Pac J Trop Dis 7(3): 129-131.

11. Hans Nesse-Global Health-SIR Model (http://www.public.asu.edu/ hnesse/cla sses/sir.html Alpha $=0.023 \&$ Beta $=0.01$ \&initialS=24)

12. Wu Z, \& McGoogan J M. (2020). Characteristics of and important lessons from the coronavirus disease 2019 (COVID-19) outbreak in China: summary of a report of 72314 cases from the Chinese Center for Disease Control and Prevention. Jama 323(13): 1239-1242.

13. Surveillances V (2020). The epidemiological characteristics of an outbreak of 2019 novel coronavirus diseases (COVID-19) China, China CDC Weekly 2(8): 113-122.

14. Wong JY, Heath Kelly DK, Wu JT, Leung GM, \& Cowling BJ (2013) Case fatality risk of influenza A (H1N1pdm09): a systematic review. Epidemiology (Cambridge, Mass.) 24(6).

15. Lloyd-Sherlock P, Ebrahim S, Geffen L, $\&$ McKee M (2020). Bearing the brunt of covid-19: older people in low and middle income countries.

16. The World Factbook (2020).

17. Onder G, Rezza G, \& Brusaferro S. (2020). Case-fatality rate and characteristics of patients dying in relation to COVID-19 in Italy. Jama 323(18): 1775-1776. 